\title{
Anti-apoptotic Actions of
} Allopregnanolone and Ganaxolone Mediated Through Membrane Progesterone Receptors (PAQRs) in Neuronal Cells

\section{OPEN ACCESS}

Edited by:

Hubert Vaudry

Université de Rouen, France

Reviewed by:

Neil James MacLusky,

University of Guelph, Canada

David Chatenet,

Institut National de la Recherche

Scientifique (INRS), Canada

Suchitra Joshi,

University of Virginia, United States

*Correspondence:

Peter Thomas

peter.thomas@utexas.edu

Specialty section:

This article was submitted to Neuroendocrine Science,

a section of the journal

Frontiers in Endocrinology

Received: 25 March 2020

Accepted: 26 May 2020

Published: 24 June 2020

Citation:

Thomas $P$ and Pang $Y$ (2020)

Anti-apoptotic Actions of Allopregnanolone and Ganaxolone

Mediated Through Membrane Progesterone Receptors (PAQRs) in Neuronal Cells.

Front. Endocrinol. 11:417. doi: 10.3389/fendo.2020.00417

\author{
Peter Thomas* and Yefei Pang \\ Marine Science Institute, University of Texas at Austin, Port Aransas, TX, United States
}

The neurosteroids progesterone and allopregnanolone regulate numerous neuroprotective functions in neural tissues including inhibition of epileptic seizures and cell death. Many of progesterone's actions are mediated through the nuclear progesterone receptor $(\mathrm{PR})$, while allopregnanolone is widely considered to be devoid of hormonal activity and instead acts through modulation of GABA-A receptor activity. However, allopregnanolone can also exert hormonal actions in neuronal cells through binding and activating membrane progesterone receptors (mPRs) belonging to the progestin and adipoQ receptor (PAQR) family. The distribution and functions of the five mPR subtypes $(\alpha, \beta, \gamma, \delta, \varepsilon)$ in neural tissues are briefly reviewed. mPR $\delta$ has the highest binding affinity for allopregnanolone and is highly expressed throughout the human brain. Low concentrations $(20 \mathrm{nM})$ of allopregnanolone act through $\mathrm{mPR} \delta$ to stimulate $\mathrm{G}$ protein $\left(\mathrm{G}_{\mathrm{S}}\right)$-dependent signaling pathways resulting in reduced cell death and apoptosis in mPR $\delta$-transfected cells. The 3-methylated synthetic analog of allopregnanolone, ganaxolone, is currently undergoing clinical trials as a promising GABA-A receptor-selective antiepileptic drug (AED). New data show that low concentrations $(20 \mathrm{nM})$ of ganaxolone also activate $\mathrm{mPR} \delta$ signaling and exert anti-apoptotic actions through this receptor. Preliminary evidence suggests that ganaxolone can also exert neuroprotective effects by activating inhibitory $G$ protein $\left(G_{i}\right)$-dependent signaling through $\mathrm{mPR} \alpha$ and/or $\mathrm{mPR} \beta$ in neuronal cells. The results indicate that mPRs are likely intermediaries in multiple actions of natural and synthetic neurosteroids in the brain. Potential off-target effects of ganaxolone through activation of mPRs in patients receiving long-term treatment for epilepsy and other disorders should be considered and warrant further investigation.

Keywords: membrane progesterone receptors, PAQR agonists, ganaxolone, allopregnanolone, inhibition apoptosis, neuronal cells, AED, neuroprotective 


\section{INTRODUCTION}

Progesterone and its metabolites produced in neural tissues (neurosteroids, Figure 1A) such as allopregnanolone mediate a wide variety of actions in the brain including neuroprotection, anti-apoptosis, inhibition of epileptic seizures, reproductive behaviors, neuroendocrine control of reproduction, and both pro-tumorigenesis and anti-tumorigenesis (1-3). Many genomic actions of progesterone in neural tissues are mediated through $\mathrm{PR}$ whereas the neurosteroid allopregnanolone has negligible binding affinity for the PR and instead interacts with GABA-A receptors resulting in decreases in their activities and also activates the pregnane $\mathrm{X}$ receptor (PXR) (3-6). However, progesterone actions have also been observed in the brain which are PR-independent (i.e., persist in PR knockout mice) and in neuronal cells which have low expression of PRs (e.g., GnRHproducing GT1-7 cells) (7-9). Evidence has accumulated that some of these actions may be mediated through membrane progesterone receptors (mPRs) $(4,10,11)$, 7-transmembrane receptors coupled to $G$ proteins belonging to the progestin and adipoQ receptor (PAQR) family which is unrelated to the GPCR superfamily $(12,13)$. Moreover, recent studies with cultured neuronal cells show that low concentrations of progesterone and allopregnanolone exert hormonal actions through binding and activating mPRs, resulting in rapid induction of intracellular signaling pathways and anti-apoptosis $(14,15)$. Collectively, these results suggest that $\mathrm{mPRs}$ are likely intermediaries of progesterone and allopregnanolone actions in neural tissues, with potential implications for human health and disease.

The mechanisms by which progesterone, allopregnanolone, and an antiepileptic drug, ganaxolone, exert their protective actions in epilepsy are summarized here. The characteristics of mPRs, their distribution in brains of humans and rodents, and their proposed functions in the central nervous system are briefly discussed. The anti-apoptotic actions of allopregnanolone in neuronal cells and in mPR-transfected cancer cells that are mediated through $\mathrm{mPR}$-dependent signaling pathways are reviewed. Ganaxolone, a synthetic analog of allopregnanolone, is currently undergoing clinical trials as a third generation AED that targets GABA-A receptors $(16,17)$. New data are presented showing that ganaxolone binds to $\mathrm{mPRs}$ and mimics the antiapoptotic actions of allopregnanolone and progesterone in these cultured cells. These results indicate that clinical studies with ganaxolone should include investigations of possible additional unexpected, off-target effects of the drug through activation of mPRs.

\section{PROTECTIVE EFFECTS OF NEUROSTEROIDS AGAINST EPILEPTIC SEIZURES}

Epilepsy is a severe neurological disorder that affects over 50 million people throughout the world $(16,18)$. Progesterone exerts anticonvulsant effects in animal epilepsy models through a PR-independent mechanism as they are not decreased in PR knockout (PRKO) mice (19). Instead, progesterone's anticonvulsant potency is increased in PRKO mice which is consistent with results showing activation of $P R$ in a status epilepticus rat model increases seizure frequency (19, 20). Progesterone's antiseizure actions are dependent on its conversion to allopregnanolone since cotreatment with the $5 \alpha$ reductase inhibitor, finasteride, blocks progesterone's actions (19). Allopregnanolone displays very weak binding affinity for PRs (21) and exerts its protective effects against seizures through a PR-independent mechanism. Allopregnanolone acts through positive allosteric modulation of GABA-A receptor activity, and can also activate the receptors at higher concentrations in the absence of GABA $(22,23)$. Positive modulation of GABA-A receptors by allopregnanolone enhances inhibitory chloride conductance which in turn decreases neuronal excitability and reduces the incidence of seizures $(19,24)$. Although over 20 AEDs have been used to treat this disease, these treatments are ineffective in controlling seizures in a third of epileptic patients and long-term treatment with enzyme-modulating AEDs can cause endocrine, metabolic, and reproductive disorders (25). The $3 \beta$-methylated synthetic analog of allopregnanolone, ganaxolone ( $3 \alpha$-hydroxy- $3 \beta$-methyl- $5 \alpha$-pregnan-20-one, Figure 1A) is a promising fourth generation AED that is currently completing phase III clinical trials (16). Ganaxolone has been shown to have activity in several animal epilepsy models and is effective in infants with spasm and in adults with partialonset seizures (17). Ganaxolone is also potentially useful for treatment of mood and anxiety disorders (16) and has been shown to improve sociability in a rodent model of autism spectrum disorder, which indicates it may increase sociability in autistic patients (26). Although ganaxolone can cause sedation in epilepsy patients, few other adverse effects of long-term administration of the drug have been observed to date in clinical trials. Methylation at the $3 \beta$ position of ganaxolone impairs its metabolism to inactive metabolites, thereby increasing its period of effectiveness in inhibiting seizures compared to allopregnanolone (26). Like allopregnanolone, ganaxolone is an allosteric modulator of GABA-A receptors and acts through different allosteric binding sites to that of benzodiazepines, as revealed by ligand binding assays and receptor mutational analysis $(17,27,28)$.

\section{MEMBRANE PROGESTERONE RECEPTORS (mPRs, PAQRs)}

Progesterone exerts hormonal actions in numerous cell and animal models through activation of membrane progesterone receptors ( $\mathrm{mPRs}$ ) belonging to the progesterone and adipoQ receptor (PAQR) family (29). These novel 7-transmembrane receptors were initially discovered in teleost fish gonads and their homologs were subsequently identified in other vertebrate classes $(30,31)$. mPRs mediate rapid, non-classical progesterone actions, which are frequently non-genomic, by activating $G$ proteins and modulation of intracellular signaling pathways. The five mPR members of the PAQR family, $m P R \alpha$ (PAQR7), mPR $\beta$ (PAQR8), mPR $\gamma$ (PAQR5), mPR $\delta$ (PAQR6), and mPR $\varepsilon$ (PAQR9), have different tissue distributions, progestin binding 
A
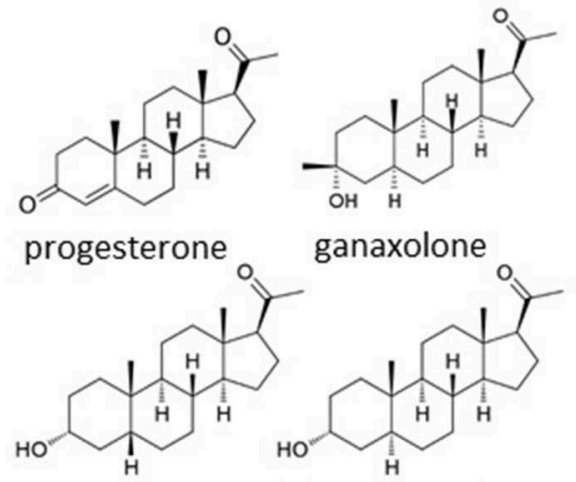

pregnanolone allopregnanolone

C

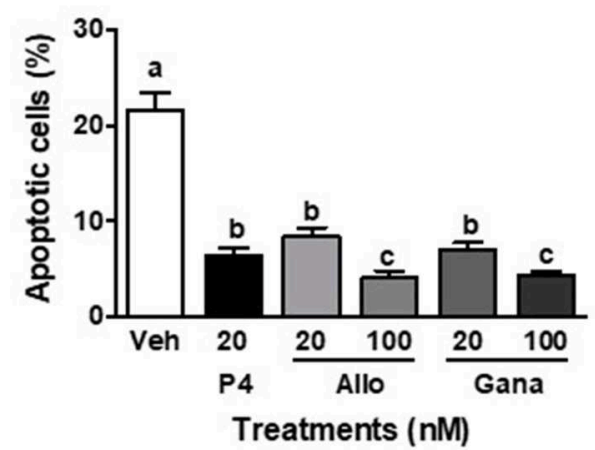

E

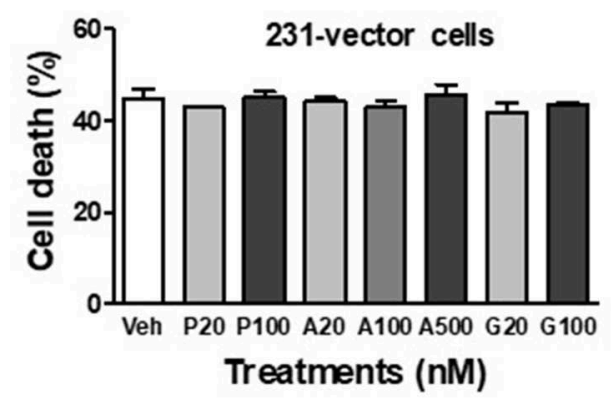

G

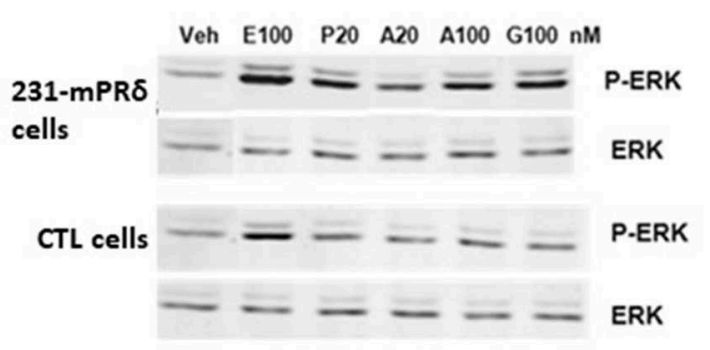

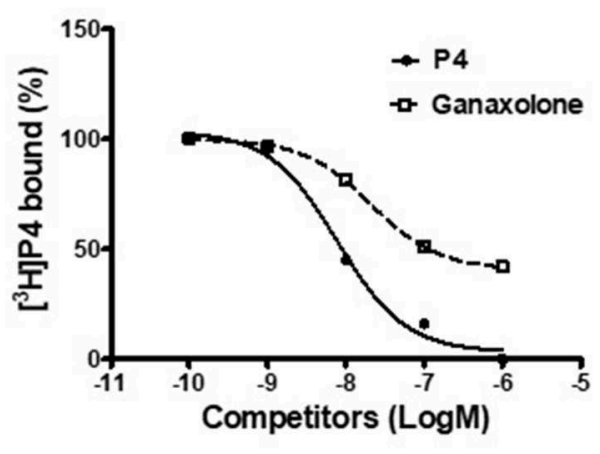

D

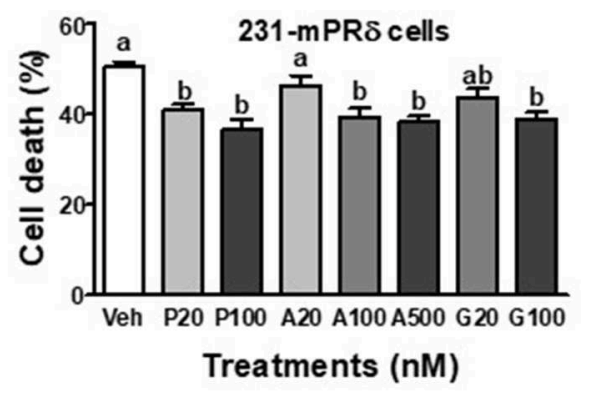

$\mathbf{F}$

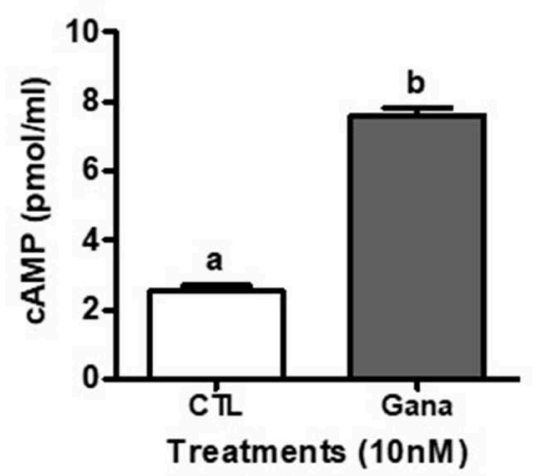

H

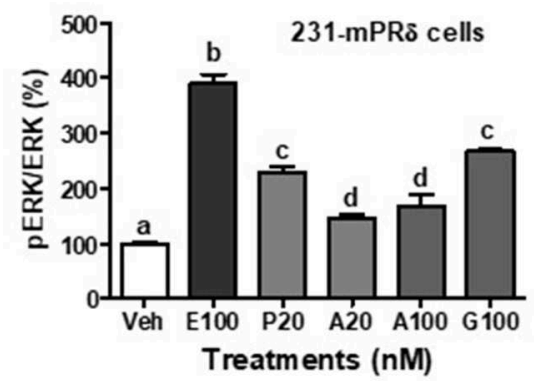

FIGURE 1 | Interactions of ganaxolone with human mPR (PAQR6). (A) Structures of ganaxolone and several other neurosteroids. (B) Representative competition curve of ganaxolone binding to plasma membranes of mPR $\delta$-transfected MDA-MB-231 cells (231-mPR $\delta$ ) expressed as percentage of maximum $\left[{ }^{3} \mathrm{H}\right]$-progesterone binding. Ganaxolone was added to the assay buffer dissolved in ethanol. Ethanol was $0.1 \%$ of total volume, which did not affect $\left[{ }^{3} \mathrm{H}\right]$-progesterone binding. $\mathrm{P} 4$, 
FIGURE 1 | progesterone. (C,E,F) Effects of 4 days treatment with progesterone (P4), allopregnanolone (Allo) and ganaxolone (Gana) on serum starvation-induced percent apoptotic cells detected with a TUNEL assay kit (C) and percent cell death detected by trypan blue staining (E,F) of the vector-transfected MDA MB-231 cells and $231-\mathrm{mPR} \delta$ cells, $N=3$. (D) Effect of treatment with ganaxolone $(10 \mathrm{nM})$ for $15 \mathrm{~min}$. on cellular cAMP levels in 231 -mPR $\delta$ cells. $N=3$. (G,H) Representative Western blot analysis and quantification of effects of 20-min treatments with progesterone (P), allopregnanolone (A), and ganaxolone (G) on activation of ERK. P-ERK: phosphorylated ERK, ERK: total ERK in the vector- (CTL cells), and 231-mPR cells. E100: 100 nM EGF as a positive control. The bar graph shows relative densitometry changes of the bands in Western blot images $(N=3)$. Results were analyzed by one-way ANOVA, followed by Newman-Keul's multiple comparison test. Treatment groups that are significantly different from each other in the post hoc test $(P<0.05)$ are indicated by different letters. Experiments were repeated three or more times, and similar results and similar significant differences between treatment groups were obtained on each occasion. See Pang et al. (15) for descriptions of reagents, culture conditions and assay procedures.

A

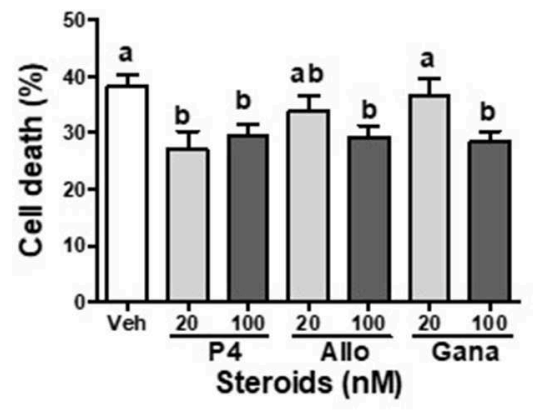

B

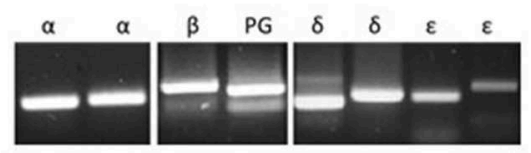

C
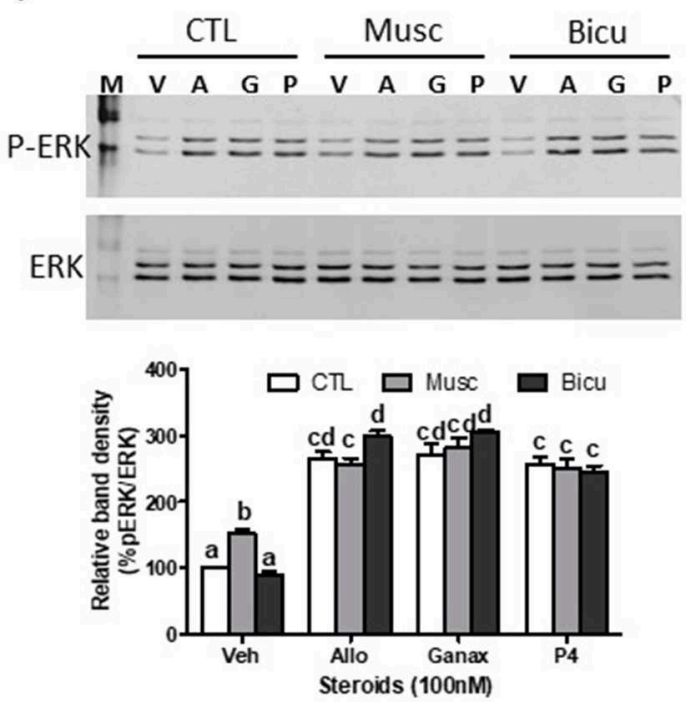

D

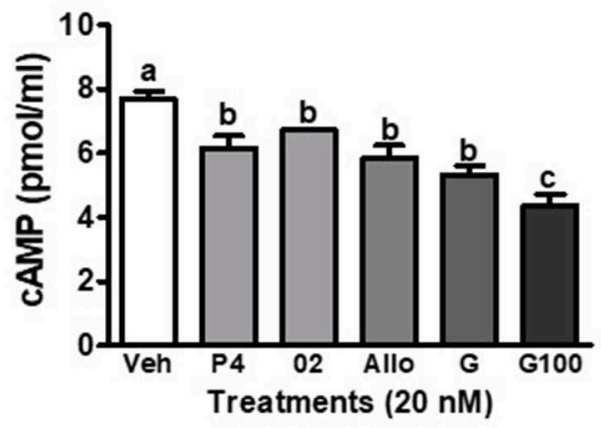

FIGURE 2 | Effects of ganaxolone on rodent neuronal cell lines. (A) Effects of 4 days treatment with $20 \mathrm{nM}$ and $100 \mathrm{nM}$ progesterone (P4), allopregnanolone (Allo) and ganaxolone (Gana) on cell death of mouse hypothalamic GT1-7 cells. $N=3$. (B) Detection of $\mathrm{mPR} \alpha(\alpha), \mathrm{mPR} \beta(\beta), \mathrm{mPR} \delta(\delta)$, mPRe $(\varepsilon)$, and progesterone receptor membrane component 1, PGRMC1 (PG) mRNA expression by RT-PCR in immortalized rat hippocampal H19-7 cells. (C) Representative Western blot analysis of effects of pre-incubation with muscimol (Musc, $100 \mu \mathrm{M}$ ) and bicuculline (Bicu, $1 \mu \mathrm{M}$ ) for $20 \mathrm{~min}$ on neurosteroid-induced (100 nM, for $20 \mathrm{~min}$.) activation of ERK. P-ERK, phosphorylated ERK; ERK, total ERK in H19-7 cells; V, vehicle control; A, allopregnanolone; G, ganaxolone; P, progesterone. The bar graph shows relative densitometry changes of the bands in Western blot images $(N=3)$. (D) Effects of 15 min. treatments with $20 \mathrm{nM}$ progesterone (P4), Org OD 02-0 (02), allopregnanolone (Allo) and ganaxolone (G, 20 and $100 \mathrm{nM}$ ) on cAMP levels in H19-7 cells. $(N=3)$. Results were analyzed by one-way ANOVA, followed by Newman-Keul's multiple comparison test. Treatment groups that are significantly different from each other in the post hoc test $(P<0.05)$ are indicated by different letters. Experiments were repeated three or more times, and similar results and similar significant differences between treatment groups were obtained on each occasion. See Pang et al. (15) for descriptions of reagents, culture conditions, and assay procedures.

specificities, signal transduction pathways, and functions in vertebrate cells and tissues (12-15). $\operatorname{mPR} \alpha$ is the predominant $\mathrm{mPR}$ isoform expressed in most progesterone target tissues with the exception of the brain and is the primary $\mathrm{MPR}$ that regulates several critical reproductive and non-reproductive progestin functions. For example, $\operatorname{mPR} \alpha$ mediates oocyte meiotic maturation and sperm motility in fish, anti-apoptosis in fish ovarian granulosa cells and in human breast cancer 
cells $(32,33)$, relaxation of human myometrial and vascular muscle cells $(34,35)$, reversal of epithelial to mesenchymal transition in breast cancer cells (36), and inhibition of prolactin release from rat lactotrophs through activation of TGF $\beta 1$ (37).

\section{LOCALIZATION OF mPRs IN THE BRAIN AND PERIPHERAL NERVOUS SYSTEM}

All five mPRs subtypes are expressed throughout the human brain and relative expression of $\mathrm{mPR} \delta \mathrm{mRNA}$ is highest among all the mPRs in nearly all brain regions, with greatest expression in the corpus callosum, hypothalamus, and spinal cord. Furthermore, mPR $\delta$ mRNA expression is greater than the mRNA expression of the other mPRs in the neocortex lobes, the limbic system (amygdala, hippocampus, nucleus accumbens), thalamus, as well as in the caudate and putamen, substantia nigra, medulla, and pons, brain regions involved in memory and movement, reward, and autonomic functions (15). Expression of $\operatorname{mPR} \beta$ and $\operatorname{mPR} \varepsilon$ genes is also high in many of these regions, including the hypothalamus, hippocampus, caudate, cerebellum, pons, and spinal cord, whereas $\mathrm{mPR} \alpha$ expression is lower in most brain regions with highest expression in the temporal lobe, medulla, and spinal cord and $\mathrm{mPR} \gamma$ expression is low throughout the brain with the exception of the pons, spinal cord and choroid plexus. The finding that PR mRNA is also expressed throughout the human brain indicates the potential for interactions between $\mathrm{mPRs}$ and $\mathrm{PR}$ in progesterone regulation of brain functions. However, PR mRNA expression is lower than that of the mPRs in all brain regions except in the pituitary gland which also expresses high levels of mPRe (15).

Unfortunately, the only information currently available on $\operatorname{mPR} \delta$ and $\mathrm{mPR} \varepsilon$ expression in rodent brains is in the mouse hypothalamus, where low mRNA levels of these subtypes and $\operatorname{mPR} \gamma$ were detected, $<10 \%$ those of $\mathrm{mPR} \alpha$ and $\operatorname{mPR} \beta$ (38). However, $\operatorname{mPR} \alpha$ and $\operatorname{mPR} \beta$ are broadly distributed in rat and mouse brains (4), with $\mathrm{mPR} \alpha$ expression detected in the hippocampus, cerebellum, hypothalamus, thalamus, cortex, striatum, and olfactory bulb (39). Higher mRNA expression of $\operatorname{mPR} \beta$ compared to that of $\mathrm{mPR} \alpha$ and high immunoreactive $\operatorname{mPR} \beta$ protein expression have been reported in the cortex, paraventricular, and preoptic regions of the hypothalamus, the oculomotor nucleus in the mesencephalon, with substantial expression also in the telencephalon, hippocampus, thalamus, and pons of female rat brains $(40,41)$. Although these two mPR subtypes are expressed only in neurons under normal conditions, $\mathrm{mPR} \alpha$ is also expressed in oligodendrocytes, astrocytes and glial cells after traumatic brain injury, suggesting a potential role for the receptor in inflammatory responses and myelin repair (39). Similarly, $\mathrm{mPR} \alpha$ is expressed in astrocytes, oligodendrocytes and their progenitor cells as well as in neurons throughout the spinal cord, whereas $\operatorname{mPR} \beta$ has a more limited distribution and is mainly located in ventral horn neurons and neurites (42). Interestingly, in the peripheral nervous system all five
mPR isoforms have been detected in Schwann cells (43). Collectively, these results indicate that progesterone and possibly allopregnanolone can act in all human brain regions through $\mathrm{mPRs}$ and suggest that different $\mathrm{mPR}$ subtypes are major intermediaries in these neurosteroid actions within distinct brain regions.

\section{FUNCTIONS OF mPRs IN THE BRAIN AND PERIPHERAL NERVOUS SYSTEM}

Although relatively few studies have been conducted so far on $\mathrm{mPR}$ functions in the brain, there is emerging evidence that they are intermediaries in several important progesterone neural functions. Experiments in new-born rats with the mPR-selective agonist, Org OD 02-0 (02-0) and in adults injected with $\mathrm{mPR} \beta$ si-RNA show that the receptor is involved in stabilizing breathing and reducing apnea (9, $44,45)$. Knockdown of $\operatorname{mPR} \beta$ and $\operatorname{mPR} \alpha$ mRNAs in the midbrains of female adult rodents by injection of antisense oligonucleotides into the lateral ventricle decreased reproductive behaviors (lordosis and aggression/rejection), whereas other behaviors were not affected $(10,46)$. The mPR agonist, 020 , increases dopamine release from hypothalamic explants of rodent prolactinoma models resulting in decreased prolactin secretion and also exerts a direct action on $\mathrm{mPR} \alpha$ in pituitary lactotrophs to decrease prolactin secretion through TGF $\beta-1$ $(37,38)$. These results suggest $\mathrm{mPR}$ agonists are potentially of therapeutic use for treating pathological hyperprolactinemia (47). However, the role of mPRs in tumorigenesis in the brain remains unclear. Whereas, proliferation and invasion of glioblastoma cells was stimulated by $02-0$ and decreased when $\mathrm{mPR} \alpha$ expression was silenced (48), progesterone has been shown to inhibit the growth and metastasis of PR-null breast cancer cells through $\mathrm{mPR} \alpha$ in the brains of nude mice (49). Several mPR functions have also been identified in the peripheral nervous system. A recent study showed migration and proliferation of primary rat Schwann cells in vitro were increased by treatment with the MPR agonist, 02-0 (50). This treatment also increased expression of differentiation markers and caused morphological changes characteristic of the repair phenotype, indicating a potential role of mPRs in peripheral nerve regeneration following injury (50). Activation of mPRs has also been shown to promote neurite growth in PC12 cells (51).

\section{INTERACTIONS OF ALLOPREGNANOLONE WITH mPRs}

We have shown that allopregnanolone exerts protective effects through mPR-dependent signaling pathways in cultured breast cancer cells that do not express PR or GABA-A receptors as well as in neuronal cells $(14,15)$. Among the mPRs allopregnanolone displays the highest binding affinity for $\mathrm{mPR} \delta$ in transfected MDA-MB-231 triple negative breast cancer cells (231-mPR $\delta$ ) with an IC50 of $151 \mathrm{nM}$ and a relative binding affinity (RBA) of $33.6 \%$ that of progesterone. 
Allopregnanolone is also an effective competitor for $\left[{ }^{3} \mathrm{H}\right]$ progesterone binding to $\mathrm{mPR} \alpha$ and $\mathrm{mPR} \beta$, with IC50s of 400 and $550 \mathrm{nM}$, respectively, whereas it has negligible binding affinity for mPR $\varepsilon$. Another neurosteroid, $5 \alpha$-dihydroprogesterone, also displays high binding affinity for $\mathrm{mPR} \alpha$ (13). Interestingly, the neurosteroids, dehydroepiandrosterone and pregnanolone (52) (Figure 1A), have relatively high binding affinities for $\mathrm{mPR} \delta$, with IC50s of 780 and $346 \mathrm{nM}$, respectively (15). A low concentration of allopregnanolone $(20 \mathrm{nM})$ was shown to mimic the stimulatory actions of progesterone on cAMP production and ERK phosphorylation and also attenuate serum starvation-induced cell death and apoptosis in 231$\mathrm{mPR} \delta$ cells cultured in vitro. Allopregnanolone $(20 \mathrm{nM})$ also decreased apoptosis of rat hippocampal neuronal (H19-7) cells which express $\mathrm{mPR} \delta$ and $\mathrm{mPR} \varepsilon$, whereas the PR agonist R5020 was ineffective. Interestingly, allopregnanolone also mimicked the actions of progesterone in cultured rat $\mathrm{GnRH}$ secreting GT1-7 cells which express high levels of $\mathrm{mPR} \alpha$ and $\operatorname{mPR} \beta$ and lower expression of mPR $\delta$ mRNA to decrease cAMP production and attenuate cell death and apoptosis (14). The finding that allopregnanolone causes a decrease in cAMP production in GT1-7 cells suggests it is acting through $\mathrm{mPR} \alpha$ and/or $\mathrm{mPR} \beta$ which activate a Gi in these cells, rather than through $\mathrm{mPR} \delta$ which activates a stimulatory G protein $(7,15)$. Collectively, these results suggest that low physiological concentrations of allopregnanolone can also potentially act through $\mathrm{mPR} \alpha / \mathrm{mPR} \beta$ to influence their neural functions. On the basis of these findings we hypothesized that ganaxolone can similarly alter neuronal cell functions mediated by mPRs. Therefore, in the present study we investigated whether ganaxolone binds to mPRs, activates mPR-dependent signaling, and exerts anti-apoptotic actions in several neuronal cell lines and in mPR-transfected cells. Experiments were conducted primarily with $231-\mathrm{mPR} \delta$ cells, since $\mathrm{mPR} \delta$ displays the highest binding affinity for allopregnanolone, following experimental procedures described in detail previously (15).

\section{INTERACTIONS OF GANAXOLONE WITH mPRs}

The present results show that ganaxolone also binds to mPRs and displays agonist activity in 231-mPR $\delta$ cells that do not express $\mathrm{GABA}_{\mathrm{A}}$ receptors (Figure 1). A representative competitive binding assay showed that ganaxolone displaced up to $60 \%$ of $\left[{ }^{3} \mathrm{H}\right]$-progesterone binding to cell membranes of 231 -mPR $\delta$ cells (Figure 1B) with an approximate IC50 of $100 \mathrm{nM}$, similar to that for allopregnanolone (15). However, the ganaxolone competition curve was not parallel to that of progesterone and higher ganaxolone concentrations $\left(10^{-7}\right.$ and $\left.10^{-6} \mathrm{M}\right)$ were ineffective in displacing the remaining $\sim 40 \%$ of $\left[{ }^{3} \mathrm{H}\right]$-progesterone binding. Similarly, a previous study showed that higher concentrations of allopregnanolone $\left(10^{-6}\right.$ and $\left.10^{-5} \mathrm{M}\right)$ did not replace the residual $30 \%\left[{ }^{3} \mathrm{H}\right]$-progesterone binding to mPR $\delta(15)$. One possible interpretation of the results is that these two neurosteroids do not occupy all the progesterone binding sites on mPR $\delta$.
However, additional research on their potential binding to allosteric sites as well as their interactions with progesterone binding to orthosteric sites will be required to determine the nature of their interactions with $\mathrm{mPR} \delta$, and whether, for example, they act as ago-allosteric ligands $(28,53,54)$. The results indicate that ganaxolone, like allopregnanolone, can potentially influence progesterone signaling through $\mathrm{mPR} \delta$. The finding that a low concentration of ganaxolone $(20 \mathrm{nM})$ mimicked the effects of $20 \mathrm{nM}$ progesterone and allopregnanolone on inhibition of serum starvation-induced apoptosis (Figure 1C) and cell death in 231-mPR $\delta$ cells (Figure 1E), whereas it was ineffective in reducing cell death in vector-transfected 231 cells (231-vector, Figure 1F) demonstrates that ganaxolone has a $\mathrm{mPR} \delta$ agonist activity at low $\mathrm{nM}$ concentrations. While the progesterone-induced decreases in the two assays were similar (10-12\% of the cells), percent cell death measured by trypan blue exclusion was higher than the percent apoptotic cells, which was expected because this assay does not distinguish between cell mortality and cell morbidity after serum starvation, whereas the TUNEL assay is a more robust measure of cells undergoing programed cell death (33). Ganaxolone triggers the same intracellular signaling pathways as those activated by progesterone and allopregnanolone. Ganaxolone treatment $(10 \mathrm{nM})$ increased cAMP levels more than two-fold over no treatment control values in $231-\mathrm{mPR} \delta$ cells, consistent with previous results showing $\mathrm{mPR} \delta$ activates a stimulatory $G$ protein (Figure 1D) (15). Ganaxolone (100 nM) ganaxolone mimicked the effects of progesterone and allopregnanolone on phosphorylation of ERK in 231-mPR $\delta$ cells (Figures 1G,H). At the higher concentration $(100 \mathrm{nM})$, ganaxolone also mimicked the inhibitory effects of progesterone and allopregnanolone on serum starvation-induced cell death in rat hypothalamic GT17 cells (Figure 2A). GT1-7 cells do not express appreciable amounts of PR mRNA in the absence of estrogen priming, but display significant expression of $\mathrm{mPR} \alpha$ and $\mathrm{mPR} \beta$ which have relatively high binding affinities for allopregnanolone, and lower expression of $\operatorname{mPR} \delta(7,14,15)$. Rat hippocampal neuronal H19-7 cells, in which progesterone and allopregnanolone have previously been shown to inhibit serum starvation-induced cell death (15), have low expression of the PR and high expression of $m P R \alpha, \operatorname{mPR} \beta$ and $\operatorname{mPR} \delta$ (Figure 2B). All three neurosteroids caused significant phosphorylation of ERK in H19-7 cells (Figure 2C). Moreover, MAP kinase signaling and its activation by ganaxolone and the two other neurosteroids was not altered by pretreatment with $100 \mu \mathrm{M}$ muscimol, a GABA-A receptor agonist, or with $1 \mu \mathrm{M}$ bicuculline, a GABA-A receptor antagonist (Figure 2C), confirming that activation of this pathway by these neurosteroids in H19-7 cells is not mediated through a GABA-A receptor. Moreover, the finding that the PR agonist R5020 does not have the anti-apoptotic effects observed with progesterone and allopregnanolone in H19-7 cells (15), suggests the PR is not involved in this response. Interestingly, treatments with $20 \mathrm{nM}$ ganaxolone and allopregnanolone mimicked the effects of progesterone and the mPR-selective agonist, 02-0, to decrease cAMP production in H19-7 cells (Figure 2D), indicating an inhibitory G protein is activated. These results suggest these neurosteroids act 
through $\mathrm{mPR} \alpha$ and/or $\mathrm{mPR} \beta$ in $\mathrm{H} 19-7$ cells, rather than through $\mathrm{mPR} \delta$, since $\mathrm{mPR} \alpha$ and $\operatorname{mPR} \beta$ activate inhibitory G proteins.

\section{DISCUSSION}

There is an extensive body of literature describing neuroprotective functions of progesterone and allopregnanolone mediated through the PR and GABA-A receptors, respectively. Our results suggest that allopregnanolone and the synthetic neurosteroid, ganaxolone, can also exert protective functions in cultured neuronal cells through activation of mPRs to attenuate cell death and apoptosis. However, details of the signaling pathways activated by these steroids through mPRs in neuronal cells are lacking. Moreover, only limited information is currently available on the functions of mPRs in the central nervous system and there is an urgent need to determine whether these neurosteroids exert similar neuroprotective functions through mPRs in in vivo models of neurodegenerative diseases. Information is also lacking on possible interactions between $\mathrm{mPR}$ and other progesterone and allopregnanolone signaling pathways mediating neuroprotective functions in neural tissues. For example, progesterone membrane component 1, which is abundant in many brain regions (4) and has been proposed to mediate progesterone neuroprotective actions (55), acts as an adaptor protein for $\mathrm{mPR} \alpha$ in breast cancer cells, by coupling to $\mathrm{mPR} \alpha$ and facilitating its transport to the cell surface where it mediates its membrane receptor functions (56). In addition, cross-talk between $\mathrm{mPR}$ and PR signaling has been shown in human myometrial cells and in rat Schwann cells. Activation of $\mathrm{mPR}$ in myometrial cells causes transactivation of $\mathrm{PR}$ and modulation of PR coactivator expression (34). On the other hand, experiments with the PR agonist, R5020, show $\mathrm{mPR} \alpha$

\section{REFERENCES}

1. Mani SK, Blaustein JD. Neural progestin receptors and female sexual behavior. Neuroendocrinology. (2012) 96:152-61. doi: 10.1159/000338668

2. Melcangi RC, Panzica GC. Allopregnanolone: state of the art. Prog Neurobiol. (2014) 113:1-5. doi: 10.1016/j.pneurobio.2013.09.005

3. González SL, Coronel MF, Raggio MC, Labombarda F. Progesterone receptormediated actions and the treatment of central system disorders: an update of the known and the challenge of the unknown. Steroids. (2020) 153:108525. doi: 10.1016/j.steroids.2019.108525

4. Guennoun R, Labombarda F, Gonzalez Deniselle MC, Liere P, De Nicola AF, Schumacher M. Progesterone and allopregnanolone in the central nervous system: response to injury and implication for neuroprotection. J. Steroid Biochem. Mol. Biol. (2015) 146:48-61. doi: 10.1016/j.jsbmb.2014. 09.001

5. Lamba V, Yasuda K, Lamba JK, Assem M, Davila J, Strom S, et al. PXR (NR1I2): splice variants in human tissues, including brain, and identification of neurosteroids and nicotine as PXR activators. Toxicol. Appl. Pharmacol. (2004) 199:251-65. doi: 10.1016/j.taap.2003.12.027

6. Langmade SJ, Gale SE, Frolov A, Mohri I, Suzuki K, Mellon SH, et al. Pregnane $\mathrm{X}$ receptor (PXR) activation: a mechanism for neuroprotection in a mouse model of Niemann-Pick C disease. Proc. Natl. Acad. Sci. USA. (2006) 103:13807-12. doi: 10.1073/pnas.0606218103

7. Sleiter N, Pang Y, Park C, Horton TH, Dong J, Thomas P, et al. Progesterone receptor A (PRA) and PRB-independent effects of progesterone and $\operatorname{mPR} \beta$ expression in rat primary Schwann cells can be upregulated through the PR (50). Finally, it is important to obtain a clearer understanding of possible off-target effects of ganaxolone through activation of $\mathrm{mPRs}$ which would indicate several additional physiological functions that should be monitored in future clinical trials as well as suggesting potential medical complications for some epilepsy patients after long-term ganaxolone treatment.

\section{DATA AVAILABILITY STATEMENT}

The raw data supporting the conclusions of this article will be made available by the authors, without undue reservation.

\section{AUTHOR CONTRIBUTIONS}

The manuscript was written by PT and edited by YP. This study was designed by PT and the experiments were conducted and analyzed by YP. The interpretation of the results was conducted by PT and YP. All authors contributed to the article and approved the submitted version.

\section{FUNDING}

This research was funded by the H.E.B. Endowed Chair in Marine Science to PT.

\section{ACKNOWLEDGMENTS}

We thank Ms. Jing Dong for assistance with cell culture and experiments and Drs. Luca Castelnovo, Aubrey Converse, and Laura Jenkins for their helpful comments on the manuscript. on gonadotropin-releasing hormone release. Endocrinology. (2009) 150:383344. doi: 10.1210/en.2008-0774

8. Reddy DS, Gangisetty O, Wu X. PR-independent neurosteroid regulation of $\alpha 2$-GABA-A receptors in three hippocampus subfields. Brain Res. (2017) 1659:142-7. doi: 10.1016/j.brainres.2017.01.030

9. Joseph V, Uppari NP, Kouci H, De Bruyn C, Boukari R, Bairam A. Respiratory regulation by steroids in newborn rats: a sex-specific balance between allopregnanolone and progesterone receptors. Exp. Physiol. (2018) 103:27690. doi: 10.1113/EP086716

10. Frye CA, Walf AC, Kohtz AS, Zhu Y. Progesterone-facilitated lordosis of estrogen-primed mice is attenuated by knocking down membrane progestin receptors in the midbrain. Steroids. (2014) 81:17-25. doi: 10.1016/j.steroids.2013.11.009

11. Liu B, Arbogast LA. Gene expression profiles of intracellular and membrane progesterone receptor isoforms in the medial basal hypothalamus during pro-oestrus. J. Neuroendocrinol. (2009) 21:993-1000. doi: 10.1111/j.1365-2826.2009.01920.x

12. Tang YT, Hu T, Arterburn $\mathrm{M}$, Boyle B, Bright JM, Emtage PC, et al. PAQR proteins: a novel membrane receptor family defined by an ancient 7-transmembrane pass motif. J Mol Evol. (2005) 61:37280. doi: $10.1007 /$ s00239-004-0375-2

13. Thomas P, Pang Y, Dong J, Groenen P, Kelder J, de Vlieg J, et al. Steroid and $G$ protein binding characteristics of the seatrout and human progestin membrane receptor $\alpha$ subtypes and their evolutionary origins. Endocrinology. (2007) 148:705-18. doi: 10.1210/en.2006-0974 
14. Thomas P, Pang Y. Membrane progesterone receptors (mPRs): evidence for neuroprotective neurosteroid signaling and neuroendocrine functions in neuronal cells. Neuroendocrinology. (2012) 96:16271. doi: $10.1159 / 000339822$

15. Pang Y, Dong J, Thomas P. Characterization, neurosteroid binding and brain distribution of human membrane progesterone receptors $\delta$ and $\varepsilon$ (mPR $\delta$ and $\mathrm{mPR} \varepsilon$ ) and $\mathrm{mPR} \delta$ involvement in neurosteroid inhibition of apoptosis. Endocrinology. (2013) 154:283-95. doi: 10.1210/en.2012-1772

16. Mula M. Emerging drugs for focal epilepsy. Expert Opin Emerg Drugs. (2018) 23:243-9. doi: 10.1080/14728214.2018.1527903

17. Nohria V, Giller E. Ganaxolone. Neurotherapeutics. (2007) 4:102-5. doi: 10.1016/j.nurt.2006.11.003

18. Tomson T, Walczak T, Sillanpaa M, Sander JW. Sudden unexpected death in epilepsy: a review of incidence and risk factors. Epilepsia. (2005) 46(Suppl 11):54-61. doi: 10.1111/j.1528-1167.2005.00411.x

19. Reddy DS, Castaneda DC, O’Malley BW, Rogawski MA. Anticonvulsant activity of progesterone and neurosteroids in progesterone receptor knockout mice. J Pharmacol Exp Ther. (2004) 310:230-9. doi: 10.1124/jpet.104. 065268

20. Shiono S, Williamson J, Kapur J, Joshi S. Progesterone receptor activation regulates seizure susceptibility. Ann Clin Translat Neurol. (2019) 6:130210. doi: 10.1002/acn3.50830

21. Iswari $\mathrm{S}$, Colas $\mathrm{AE}$, Karavolas HJ. Binding of $5 \alpha$-dihydroprogesterone and other progestins to female rat anterior pituitary nuclear extracts. Steroids. (1986) 47:189-203. doi: 10.1016/0039-128X(86) 90088-7

22. Belelli D, Lambert JJ. Neurosteroids: endogenous regulators of the GABA receptor. Nat Rev Neurosci. (2005) 6:565-75. doi: 10.1038/nrn1703

23. Wu YV, Burnham WM. Progesterone, 5 $\alpha$-dihydroprogesterone and allopregnanolone's effects on seizures: a review of animal and clinical studies. Seizure-Eur J Epilep. (2018) 63:26-36. doi: 10.1016/j.seizure.2018.10.012

24. Joshi S, Kapur J. Neurosteroid regulation of $\mathrm{GABA}_{\mathrm{A}}$ receptors: a role in catamenial epilepsy. Brain Res. (2019) 1703:31140. doi: 10.1016/j.brainres.2018.02.031

25. Luef G, Rauchenzauner M. Epilepsy and hormones: a critical review. Epilepsy Behav. (2009) 15:73-7. doi: 10.1016/j.yebeh.2009.02.022

26. Saporito MS, Gruner JA, DiCamillo A, Hinchliffe R, Barker-Haliski M, White HS. Intravenously administered ganaxolone blocks diazepinresistant lithium-pilocaprine-induced status epilepticus in rats: comparison with allopregnanolone. J Pharmacol Exp Ther. (2019) 368:326-37. doi: 10.1124/jpet.118.252155

27. Chuang SH, Reddy DS. 3 $\beta$-methyl-neurosteroid analogs are preferential positive allosteric modulators and direct activators of extrasynaptic $\gamma$-aminobutyric acid type A receptors in the hippocampus dentate gyrus subfield. J Pharmacol Exp Ther. (2018) 365:583-601. doi: 10.1124/jpet.117.246660

28. Alanis BAV, Iorio MT, Silva LL, Bampali K, Ernst M, Schnürch M, et al. Allosteric GABAa receptor modulators-A review on the most recent heterocyclic chemotypes and their synthetic accessibility. Molecules. (2020). 25:999. doi: 10.3390/molecules25040999

29. Thomas P. Characteristics of membrane progestin receptor alpha $(\mathrm{mPR} \alpha)$ and progesterone membrane receptor component one (PGMRC1) and their roles in mediating rapid progestin actions. Front Neuroendocrinol. (2008) 29:292-312. doi: 10.1016/j.yfrne.2008.01.001

30. Zhu Y, Rice CD, Pang Y, Pace M, Thomas P. Cloning, expression, and characterization of a membrane progestin receptor and evidence it is an intermediary in meiotic maturation of fish oocytes. Proc Natl Acad Sci USA. (2003) 100:2231-6. doi: 10.1073/pnas.0336132100

31. Zhu Y, Bond J, Thomas P. Identification, classification, and partial characterization of genes in humans and other vertebrates homologous to a fish membrane progestin receptor. Proc Natl Acad Sci USA. (2003) 100:223742. doi: 10.1073/pnas.0436133100

32. Dressing GE, Pang Y, Dong J, Thomas P. Progestin signaling through $\mathrm{mPR} \alpha$ in Atlantic croaker granulosa/theca cell cocultures and its involvement in progestin inhibition of apoptosis. Endocrinology. (2010) 151:591626. doi: 10.1210/en.2010-0165

33. Dressing GE, Alyea R, Pang Y, Thomas P. Membrane progesterone receptors (mPRs) mediate antimorbidity in breast cancer cells and are expressed in human breast tumors. Horm Cancer. (2012) 3:10112. doi: 10.1007/s12672-012-0106-x

34. Karteris E, Zervou S, Pang Y, Dong J, Hillhouse EW, Randeva HS, et al. Progesterone signaling in human myometrium through two novel membrane $G$ protein-coupled receptors: potential role in functional progesterone withdrawal at term. Mol Endocrinol. (2006) 20:1519-34. doi: 10.1210/me.2005-0243

35. Pang $\mathrm{Y}$, Thomas $\mathrm{P}$. Progesterone induces relaxation of vascular smooth muscle cells through $\mathrm{mPR} \alpha$ (PAQR7). Mol Cell Endocrinol. (2018) 474:2034. doi: 10.1016/j.mce.2018.02.003

36. Zuo L, Li W, You S. Progesterone reverses the mesenchymal phenotypes of basal phenotype breast cancer cells via a membrane progesterone receptor pathway. Breast Cancer Res. (2010) 12:R34. doi: 10.1186/bcr2588

37. Camilletti MA, Ferraris J, Abeledo-Machado A, Converse A, Faraoni E, Pisera D, et al. Participation of membrane progesterone receptor $\alpha$ in the inhibitory effect of progesterone on prolactin secretion. J Neuroendocrinol. (2018) 30:1-15. doi: 10.1111/jne.12614

38. Camilletti MA, Abeledo-Machado A, Perez PA, Faraoni EY, De Fino F, Rulli SB, et al. mPRs represent a novel target for PRL inhibition in experimental prolactinomas. Endocr Relat Cancer. (2019) 26:497510. doi: 10.1530/ERC-18-0409

39. Meffre D, Labombarda F, Delespierre A, Chastre A, De Nicola AF, Stein DG, et al. Distribution of membrane progesterone receptor alpha in the male mouse and rat brain and its regulation after traumatic brain injury. Neuroscience. (2013) 231:111-24. doi: 10.1016/j.neuroscience.2012.11.039

40. Zuloaga DG, Yahn SL, Pang Y, Quihuis AM, Oyola MG, Reyan A, et al. Distribution and estrogen regulation of membrane progesterone receptor- $\beta$ in the female rat brain. Endocrinology. (2012) 153:443243. doi: 10.1210/en.2012-1469

41. Intlekofer KA, Petersen SL. Distribution of mRNAs encoding classical progestin receptor, progesterone membrane components 1 \&2, serpin mRNA binding protein 1 , and progestin and adipoQ receptor family members 7 and 8 in rat forebrain. Neuroscience. (2011) 172:55065. doi: 10.1016/j.neuroscience.2010.10.051

42. Labombarda F, Meffre D, Delespierre B, Krivokapic-Blondiaux S, Chastre A, Thomas $\mathrm{P}$, et al. Membrane progesterone receptors localization in the mouse spinal cord. Neuroscience. (2010) 166:94-106. doi: 10.1016/j.neuroscience.2009.12.012

43. Castelnovo LF, Magnaghi V, Thomas P. Expression of membrane progesterone receptors (mPRs) in rat peripheral glial cell membranes and their potential role in the modulation of cell migration and protein expression. Steroids. (2019) 142:6-13. doi: 10.1016/j.steroids.2017.09.009

44. Bairam A, Boukari R, Joseph V. Targeting progesterone receptors in newborn males and females: From the animal model to a new perspective for the treatment of apnea of prematurity. Respir Physiol Neurobiol. (2019) 263:5561. doi: 10.1016/j.resp.2019.03.004

45. Boukari R, Rossignol O, Baldy C, Marcouiller F, Bairam A, Joseph V. Membrane progesterone receptor- $\beta$, but not $-\alpha$, in dorsal brain stem establishes sex-specific chemoreflex responses and reduces apnea frequency in adult mice. J Appl Physiol. (2016) 121:781-91. doi: 10.1152/japplphysiol.00397.2016

46. Frye CA, Walf AA, Kohtz AS, Zhu Y. Membrane progestin receptors in the midbrain ventral tegmental area are required for progesterone-facilitated lordosis of rats. Horm Behav. (2013) 64:539-45. doi: 10.1016/j.yhbeh.2013.05.012

47. Camilletti MA, Abeledo-Macahdo A, Faraoni EY, Thomas P, Díaz-Torga G. New insight into progesterone actions on prolactin secretion and prolactinoma development. Steroids. (2019) 152:108496. doi: 10.1016/j.steroids.2019.108496

48. Gonzalez-Oroxco JC, Hansberg-Pastor V, Valdez-Cosmes P, NicolasOrtega W, Bastida-Beristain Y, Fuente-Granada M, et al. Activation of membrane progesterone receptor-alpha increases proliferation, migration, and invasion of human glioblastoma cells. Mol Cell Endocrinol. (2018) 477:81-9. doi: 10.1016/j.mce.2018.06.004

49. Zhou L, Zhou W, Zhang H, Hu Y, Yu L, Zhang Y, et al. Progesterone suppresses triple-negative breast cancer growth and metastasis to brain via membrane progesterone receptor $\alpha$. Int J Mol Med. (2017) 40:75561. doi: $10.3892 /$ ijmm.2017.3060 
50. Castelnovo LF, Caffino L, Fumagalli F, Thomas P, Magnaghi V. Membrane progesterone receptors (mPRs/PAQRs) regulate migration, proliferation and differentiation in rat Schwann cells. J Mol Neurosci. (2020) 70:43348. doi: 10.1007/s12031-019-01433-6

51. Kasubuchi $\mathrm{M}$, Watanabe $\mathrm{K}$, Hirano $\mathrm{K}$, Inoue $\mathrm{D}$, Li $\mathrm{X}$, Terasawa $\mathrm{K}$, et al. Membrane progesterone receptor beta (mPR $\beta /$ Paqr8) promotes progesterone-dependent neurite outgrowth in PC12 neuronal cells via non-G protein-coupled receptor (GPCR) signaling. Sci Rep. 7:5168. doi: 10.1038/s41598-017-05423-9

52. Baulieu EE. Steroids and brain, a rising bio-medical domain: a perspective. Front Endocrinol. 9:316. doi: 10.3389/fendo.2018.00316

53. Wenthur CJ, Gentry PR, Mathews TP, Lindley CW. Drugs for allosteric sites on receptors. Ann Rev Pharmacol Toxicol. (2014) 54:165-84. doi: 10.1146/annurev-pharmtox-010611-134525

54. Guo D, Heitman LH, IJzerman A. Kinetic aspects of the interaction between ligand and $\mathrm{G}$ protein-coupled receptor: the case of adenosine receptors. Chem Rev. (2016) 117:38-66. doi: 10.1021/acs.chemrev.6b00025

55. Cooke PS, Nanjappa MK, Yang Z, Wang KKW. Therapeutic effect of progesterone and its metabolites in traumatic brain injury may involve non-classical signaling mechanisms. Front Neurosci. (2013) 7:108. doi: 10.3389/fnins.2013.00108

56. Thomas P, Pang Y, Dong J. Enhancement of cell surface expression and receptor functions of membrane progestin receptor $\alpha(\mathrm{mPR} \alpha)$ by progesterone receptor membrane component 1 (PGRMC1): evidence for a role of PGRMC1 as an adaptor protein for steroid receptors. Endocrinology. (2014) 155:1107-19. doi: 10.1210/en.20 13-1991

Conflict of Interest: The authors declare that the research was conducted in the absence of any commercial or financial relationships that could be construed as a potential conflict of interest.

Copyright $\odot 2020$ Thomas and Pang. This is an open-access article distributed under the terms of the Creative Commons Attribution License (CC BY). The use, distribution or reproduction in other forums is permitted, provided the original author(s) and the copyright owner(s) are credited and that the original publication in this journal is cited, in accordance with accepted academic practice. No use, distribution or reproduction is permitted which does not comply with these terms. 